\title{
Patterns of Antimicrobial Resistance and ESBL Carriage in Enterobacteriaceae Isolates from Broiler Chicken in the West Region of Cameroon: A Cross- sectional Study
}

\author{
Leinyuy Jude Fonbah \\ University of Dschang \\ Innocent Mbulli Ali ( $\nabla$ dr.alinn@gmail.com ) \\ University of Dschang \\ Ousenu Karimo \\ University of Dschang \\ Christopher B. Tume \\ University of Dschang
}

\section{Research Article}

Keywords: Broilers, food-borne pathogens, Enterobacteriaceae, antibiotic resistance, multidrug resistance (MDR), extended spectrum beta lactamase (ESBL), Cameroon, West Region

Posted Date: August 5th, 2021

DOI: https://doi.org/10.21203/rs.3.rs-743570/v1

License: (1) This work is licensed under a Creative Commons Attribution 4.0 International License. Read Full License 


\section{Abstract}

Background: The emergence of multidrug-resistant foodborne pathogens of animal origin is a growing concern. In particular, antibiotic resistance in Enterobacteriaceae of clinical importance has been on the rise. Identifying and monitoring resistance patterns in residual intestinal microflora in poultry are of great significance in the containment of antimicrobial resistance. The current study aimed to detect Enterobacteriaceae among broiler chicken and determine key antibiotic resistance patterns in isolates from poultry chicken in the West Region of Cameroon.

Results: 275 cloacal swabs were collected from 28 poultry farms in 11 locations in 5 out of the 8 Divisions in the West Region. All samples tested positive for Enterobacteriaceae with an average of 3 different colonies per sample. 394 isolates were obtained belonging to 12 different Genera of Enterobacteriaceae distributed as 81 (20.56 \%) Escherichia spp, 74 (18.78 \%) Salmonella spp, 39 (9.90 \%) Klebsiella spp, 38 (9.64 \%) Proteus spp, 34 (8.63 \%) Citrobacterspp, 31 (7.87 \%) Enterobacter spp, 28 (7.87\%) Providencia spp, 19 (4.82\%) Hafnia spp, 15 (3.30 \%) Shigella spp, 14 (3.55 \%) Raoultella spp, 13 (3.30\%) Yersinia spp and 8 (1.78 \%) Morgenella spp. Antibiotic susceptibility testing on isolates showed the following overall resistance to the various antibiotics tested: amoxicillin 345 (87.8\%), amoxicillin/clavulanic acid 227 (57.8\%), ceftriaxone 79 (20.1\%), cefotaxime 65 (16.5\%), imipenem 16 (4.1\%), gentamicin 58 (14.5\%), amikacin 12 (3.1\%), ciprofloxacin $142(37.1 \%)$, levofloxacin 124 (33.1\%) and doxycycline 380 (96.7). 217 (55.1\%) were resistant to at least one antibiotic class of choice against Enterobacteriaceae, 80 (20.3\%) resistant to at least one cephalosporin, 164 (41.62 \%) resistant to at least one quinolone and $66(16.75 \%)$ resistant to at least one aminoglycoside. $173(44.0 \%)$ showed MDR and 84 (21.32 \%) were ESBL producers. Poor sanitation increased Enterobacteriaceae carriage, antibiotic misuse and long periods of rearing increased the risk of developing antimicrobial resistance, MDR and ESBL production.

Conclusion: Poor sanitation in poultries caused high Enterobacteriaceae carriage in subjects. This high coinfection coupled with antibiotic abuse caused high prevalence of resistance, MDR and ESBL production. These outcomes showed relatively uniform distribution across the area of study.

\section{Background}

Enterobacteriaceae are a Family of gram negative non-spore forming rod shaped bacteria. They are found everywhere; in soil, water, and decaying matter and also in guts of animals and humans where they can be pathogens or members of the normal intestinal microflora ${ }^{1,2}$. Antimicrobial resistance in Enterobacteriaceae is a serious threat to public health due to the association of different resistance mechanisms and the insufficient development of new drugs which make these microorganisms resistant to almost all available antibiotics ${ }^{3}$. Animal husbandry, mainly poultry and pig farming which provide food and jobs to a great number of people in this Region, are highly linked to zoonosis ${ }^{4,5}$. Chicken are an important source of contamination with clinically important human pathogens $s^{6}$, they tend to harbour extensive numbers and diverse types of enteric bacteria both commensal and pathogenic ${ }^{7}$. Such co-occurrence coupled with abuse of antibiotics in Cameroonian poultries ${ }^{8}$ give opportunity for sharing of resistance genes among species and chromosomal recombinations due to stress from antibiotics leading to emergence of resistant strains, multidrug resistance and emergent 
zoonoses $^{7,9,10}$. When antimicrobial resistance develops in commensal intestinal microflora it tends to go unchecked making these commensals to act as reservoir of antimicrobial resistance ${ }^{7}$. Thus the development of antimicrobial resistance in commensal Enterobacteriaceae of animal origin is a measure for early detection of antimicrobial resistance in the community ${ }^{11}$. Within the West Region, there are regular reports of gastrointestinal infections among patients, most of these infections are linked to Enterobacteriaceae ${ }^{12,13}$. Treatment of these diseases has been proving difficult at times due to the development of antibiotic resistance in these bacteria ${ }^{14}$. Chicken being one of the main meat types in Cameroon ${ }^{15}$ and an important source of Enterobacteriaceae infection for humans ${ }^{6}$, and bearing in mind that the development of antibiotic resistance in commensal Enterobacteriaceae of animal origin is a measure for early detection of antibiotic resistance in the community ${ }^{11}$, our quest for patterns of antibiotic resistance in Enterobacteriaceae in the West Region of Cameroon prompted us to use chicken as our sample source. This research aimed to bring out information that can attract the attention of stakeholders, including veterinarians, physicians, microbiologists, livestock producers, public health workers and relevant government agencies to the need for basic salvaging measures to curb chicken spread zoonosis. We supposed that due to the inadequacy of published works in this area, there is the development of antibiotic resistance, multidrug resistance (MDR) and extended spectrum beta lactamase $(\mathrm{ESBL})$ production among animal hosts which go unreported.

\section{Results}

\section{Evaluation of risks in farms}

Samples were collected from 28 farms in 11 locations in 5 out of the 8 Divisions in the West Region. Evaluating risks, 25 farms out of 28 regularly used antibiotics on their chicken, 138 subjects sampled were more than 30 days old and fell on the category "old" while 137 were 30 days old or less and fell in the category "young", 7 farms out of 28 regularly cleaned feeders and drinkers for the chicken, 12 farms out of 28 gave unsure water to their chicken and 18 out of 28 farms had dirty environment with or without stagnant sewage. Bacterial carriage in terms of different colony types present in culture correlated significantly with the 3 environmental risk factors evaluated.

Table 1

Information on the locations of farms, number of samples and isolates and the risk factors to which chicken subjects were exposed 


\begin{tabular}{|c|c|c|c|c|c|c|c|c|}
\hline \multirow[t]{2}{*}{ Location } & \multirow{2}{*}{$\begin{array}{l}\text { Number } \\
\text { of } \\
\text { farms }\end{array}$} & \multirow{2}{*}{$\begin{array}{l}\text { Samples } \\
\text { (1 per } \\
\text { subject) }\end{array}$} & \multirow[t]{2}{*}{ Isolates } & \multicolumn{5}{|c|}{ Evaluated risks at farms } \\
\hline & & & & $\begin{array}{l}\text { Use of } \\
\text { antibiotics }\end{array}$ & $\begin{array}{l}\text { Age of } \\
\text { subject }\end{array}$ & $\begin{array}{l}\text { Poor } \\
\text { feeding } \\
\text { hygiene }\end{array}$ & $\begin{array}{l}\text { Unsure } \\
\text { water }\end{array}$ & $\begin{array}{l}\text { Poor } \\
\text { sanitation }\end{array}$ \\
\hline $\begin{array}{l}\text { Bafoussam } \\
\text { Rural }\end{array}$ & 4 & 40 & 66 & 4 & 18,22 & $3 / 4$ & $1 / 4$ & $2 / 4$ \\
\hline $\begin{array}{l}\text { Bafoussam } \\
\text { Urban }\end{array}$ & 5 & 50 & 72 & 5 & 22,27 & $2 / 5$ & 0 & $2 / 4$ \\
\hline Batcham & 1 & 10 & 16 & 0 & 5,5 & 1 & 1 & 1 \\
\hline Balesseng & 2 & 15 & 22 & 2 & 8,7 & 2 & 2 & $1 / 2$ \\
\hline Banjoun & 3 & 30 & 44 & 3 & 18,12 & $2 / 3$ & $2 / 3$ & $1 / 3$ \\
\hline Dschang & 3 & 30 & 40 & 3 & 16,14 & $2 / 3$ & $2 / 3$ & 3 \\
\hline Foumbot & 2 & 20 & 26 & $1 / 2$ & 11,9 & 2 & $1 / 2$ & 2 \\
\hline Mbouda & 2 & 20 & 24 & 2 & 11,9 & 2 & $1 / 2$ & $1 / 2$ \\
\hline Nkong-Ni & 2 & 20 & 27 & 2 & 10,10 & 2 & 2 & 2 \\
\hline $\begin{array}{l}\text { Penka } \\
\text { Michel }\end{array}$ & 2 & 20 & 27 & 2 & 10,10 & $1 / 2$ & 2 & $1 / 2$ \\
\hline Santchou & 2 & 20 & 30 & 2 & 10,10 & $1 / 2$ & 2 & 2 \\
\hline Total & 28 & 275 & 394 & $26 / 28$ & $\begin{array}{l}138 \\
137\end{array}$ & $20 / 28$ & $\begin{array}{l}16 / \\
28\end{array}$ & $18 / 28$ \\
\hline $\begin{array}{l}\text { Percentage } \\
\text { exposure to } \\
\text { risk }\end{array}$ & & & & 92.86 & $\begin{array}{l}50.18 \\
49.81\end{array}$ & 71.43 & 57.14 & 64.29 \\
\hline
\end{tabular}

Evaluated Description

risk

Unsure Using any other source of water apart from pipe-borne water without prior treatment.

water

Use of Regular use of antibiotics in feed for chicken subjects or have used on the subject.

antibiotics

Sanitation Conditions of the environment such as litter, stagnant sewage, rearing of animals around poultry, state of workers' restroom.

Feeding Cleaning of feeders and drinkers.

hygiene

Age $\quad \leq 30$ days for category "young" and $₫ 30$ days for category "old" chicken. 
Table 2

Relationship between bacterial carriage in samples and environmental risk factors

\begin{tabular}{|lll|}
\hline & \multicolumn{1}{l}{ Bacteria carriage (number of colonies) of $\geq 3$ per sample } \\
\hline & Odds ratio $(95 \% \mathrm{Cl})$ & p value \\
\hline Poor feeding hygiene & $2.55(1.67,3.89)$ & 0.000 \\
\hline Unsure water & $1.75(1.16,2.64)$ & 0.011 \\
\hline Poor sanitation & $1.97(1.31,2.96)$ & 0.009 \\
\hline
\end{tabular}

\section{Prevalence of members of the Enterobacteriaceae}

A total of 275 cloacal swabs were collected. All these samples tested positive for Enterobacteriaceae with a carriage of at least 2 different colony types and a mean of 3 different colony types per sample. In total, 394 isolates were obtained and characterised belonging to 12 different Genera of Enterobacteriaceae. The 394 isolates were distributed as 81 (20.56 \%) Escherichia spp, 74 (18.78\%) Salmonella spp, 39 (9.90 \%) Klebsiella spp, 38 (9.64 \%) Proteus spp, 34 (8.63\%) Citrobacter spp, 31 (7.87\%) Enterobacter spp, 28 (7.87\%) Providencia spp, 19 (4.82\%) Hafnia spp, 15 (3.30 \%) Shigella spp, 14 (3.55 \%) Raoultella spp, 13 (3.30 \%) Yersinia spp and $8(1.78 \%)$ Morgenella spp.

The computed coefficient of variation of the prevalence of each organism in the various locations showed relatively uniform prevalence across locations of sampling

\section{Prevalence of antibiotic resistance}

Antibiotic susceptibility testing on isolates showed the following overall resistance to the various antibiotics tested: amoxicillin 345 (87.8\%), amoxicillin/clavulanic acid 227 (57.8\%), ceftriaxone 79 (20.1\%), cefotaxime 65 (16.5\%), imipenem 16 (4.1\%), gentamicin 58 (14.5\%), amikacin 12 (3.1\%), ciprofloxacin 142 (37.1\%), levofloxacin 124 (33.1\%), doxycycline 380 (96.7).

$173(44.0 \%)$ of the isolates showed multi drug resistance phenotype and 84 (21.32) were ESBL producers. 217 (55.1\%) of isolates were resistant to at least one antibiotic class of choice against Enterobacteriaceae (cephalosporins, carbapenems, quinolones or aminoglycosides). 80 (20.3\%) of the isolates were resistant to at least one of the cephalosporins tested, $164(41.62 \%)$ were resistant to at least one of the quinolones tested and $66(16.75 \%)$ were resistant to at least one of the aminoglycosides tested. 232 (58.88 \%) of the isolates showed penicillinase production but ESBL production was much lower with 84 (21.32\%) and 173 (43.91\%) showed MDR when considering only beta lactamins, quinolones and aminoglycosides, but adding the contribution of tetracyclines MDR rose to 85.53 \% (337 isolates). (See Table 5 Complementary tables for details of the prevalence of antibiotic resistance in various isolates)

The association of resistance to the various antibiotic classes is shown in the following diagram. 
The diagram shows that the number of ESBL producing isolates that were quinolone resistant was significantly lower than the number of isolates that were not quinolone resistant (32/84 against 52/84 respectively) while the number of aminoglycoside isolates that were resistant to quinolones was significantly higher than the number of isolates that were not quinolone resistant $(43 / 66$ against $23 / 66)$.

\section{Association of risk factors among chickens with antibiotic resistance}

The outcome "resistance" indicates isolates showing resistance to at least one antibiotic from one class of choice. The development of resistance to at least one antibiotic class correlated significantly to the age of the chicken and food hygiene. Isolates had higher risk of developing resistance on exposure to all risks except unsure water. ESBL production correlated significantly to age of chicken and isolates had higher risk of developing ESBL on exposure to all risks except use of antibiotics. MDR correlated significantly to the age of the chicken and isolates had a higher risk of developing MDR on exposure to all risks except unsure water. The risk "use of antibiotics" was quasi constant thus did not correlate with outcomes.

Table 5

Association of risks to resistance outcomes 


\begin{tabular}{|c|c|c|c|c|c|}
\hline \multicolumn{6}{|l|}{$N=394$} \\
\hline \multirow[t]{3}{*}{ Factor } & \multirow[t]{3}{*}{ Outcome } & \multicolumn{3}{|l|}{ Risk estimate } & \multirow{3}{*}{$\begin{array}{l}\text { Correlation } \\
(\text { significant correlation } \\
\leq 0.01)\end{array}$} \\
\hline & & \multirow[t]{2}{*}{$\begin{array}{l}\text { Odds ratios (increased } \\
\text { risk } \square 1 \text { ) }\end{array}$} & \multicolumn{2}{|c|}{$\begin{array}{l}95 \% \text { confidence } \\
\text { interval }\end{array}$} & \\
\hline & & & Lower & Upper & \\
\hline $\begin{array}{l}\text { Use of } \\
\text { antibiotics }\end{array}$ & Resistance & 1.394 & 0.852 & 2.280 & 0.186 \\
\hline $\begin{array}{l}\text { Age of } \\
\text { chicken }\end{array}$ & Resistance & 13.491 & 8.274 & 21.997 & 0.000 \\
\hline $\begin{array}{l}\text { Feeding } \\
\text { hygiene }\end{array}$ & Resistance & 1.783 & 1.172 & 2.714 & 0.007 \\
\hline Sanitation & Resistance & 1.495 & 1.000 & 2.234 & 0.049 \\
\hline Unsure water & Resistance & 0.709 & 0.471 & 1.065 & 0.098 \\
\hline $\begin{array}{l}\text { Use of } \\
\text { antibiotics }\end{array}$ & ESBL & 0.669 & 0.356 & 1.259 & 0.212 \\
\hline $\begin{array}{l}\text { Age of } \\
\text { chicken }\end{array}$ & ESBL & 4.505 & 2.352 & 8.626 & 0.000 \\
\hline $\begin{array}{l}\text { Feeding } \\
\text { hygiene }\end{array}$ & ESBL & 1.182 & 0.657 & 2.125 & 0.578 \\
\hline Sanitation & ESBL & 1.322 & 0.754 & 2.316 & 0.330 \\
\hline Unsure water & ESBL & 2.589 & 1.372 & 4.885 & 0.003 \\
\hline $\begin{array}{l}\text { Use of } \\
\text { antibiotics }\end{array}$ & MDR & 1.490 & 0.897 & 2.473 & 0.123 \\
\hline $\begin{array}{l}\text { Age of } \\
\text { chicken }\end{array}$ & MDR & 7.980 & 5.054 & 12.600 & 0.000 \\
\hline $\begin{array}{l}\text { Feeding } \\
\text { hygiene }\end{array}$ & MDR & 1.538 & 1.004 & 2.354 & 0.047 \\
\hline Sanitation & MDR & 1.348 & 0.900 & 2.018 & 0.148 \\
\hline Unsure water & MDR & 0.544 & 0.362 & 0.818 & 0.003 \\
\hline
\end{tabular}

\section{Discussion}

\section{Prevalence}

The sanitary conditions in the various poultries visited were average, not up to standard conditions mainly due to the nature of construction and materials used which promoted poor hygiene around the poultries. Some areas did not have pipe borne water thus farmers used well water with doubtful cleanliness. These conditions favoured extensive infection of the animals ${ }^{16,17}$. The chicken harboured a myriad of Enterobacteriaceae 
observed by the co-occurrence of an average of 3 different colony types in each sample. This is telling of the possibility of new antibiotic resistance and multidrug resistance to develop by horizontal gene transfer by means of mobile genetic materials such as plasmids or transposons ${ }^{7,18}$. There was a high prevalence of Escherichia (20.56 \%) and Salmonella (18.78\%) among the isolates followed by Klebsiella $(9.90 \%)$. These are clinically important genera with several species causing various diseases in human ${ }^{19}$. The isolation of members like Shigella even in few numbers is already a cause for concern given the virulence of the bacterium. However, their prevalence is similar to what is found elsewhere in several studies ${ }^{20,21}$. The fairly uniform prevalence of the organisms in locations studied can be explained by the uniform socio-demographic and geographical nature (grass field highlands) of the area ${ }^{22}$.

\section{Antibiotic susceptibility testing}

All the isolated Enterobacteriaceae genera tested showed a high level of resistance to amoxicillin (87.8\%) of the group of Penicillins and doxycycline $(96.7 \%)$ of the class of Tetracyclines. These results were concordant with results obtained by Tago K. G., et $a / 2013^{23}$ and further confirmed that these are no more drug classes of choice against Enterobacteriaceae. Generally, among the drug classes of choice prescribed against Enterobacteriaceae, isolates showed a higher resistance to Quinolones (37.1\% in ciprofloxacin and $31.1 \%$ in levofloxacin) compared to third generation Cephalosporins (20.1 in ceftriaxone \% and 16.5 in cefotaxime), imipenem and Aminoglycosides (3.1\% in amikacin and $14.5 \%$ in gentamicin). Compared to early reports such as $\mathrm{J}$ Robert et al, $2001^{21}$, resistance to quinolones is on the rise with for example ciprofloxacin $10 \%(90 \%$ susceptibility) in 1998 to $37.1 \%$ in the present study. The high resistance to ciprofloxacin should be monitored closely because it is one of the highest self-medications taken in simple Enterobacteriaceae related diseases and gastroenteritis in the West Region and most of parts of Cameroon owing to rampant drug misuse and self-medication in Cameroon which is not only in clinical settings but also in poultry farms ${ }^{8}$. However, the bacteria showed high susceptibilities to third generation Cephalosporins and Aminoglycosides compared to those observed elsewhere in Jamal F et al. $2011^{24}$ and Sebastien B. et al. $2016^{25}$.

There was observed a generally high MDR in all the genera with a general prevalence of $85.53 \%$. This is similar to the trend seen elsewhere as reported in Leski et al. $2016^{26}$. However considering that tetracyclines are not drugs of choice against Enterobacteriaceae ${ }^{27}$, ignoring the contribution of doxycycline this value falls considerably to $43.91 \%$. This high MDR prevalence in mostly commensal organisms like Escherichia and Proteus may go unchecked but in the face of an opportunistic infection, the treatment becomes difficult due to the developed $\mathrm{MDR}^{28}$. ESBL production was observed at fairly moderate levels but the co-development of MDR and ESBL further compounds the failure of antibiotics in disease treatment ${ }^{29}$.

Traditionally Enterobacteriaceae have developed high resistance to Penicillins via production of penicillinase ${ }^{30}$ this explains high resistance to amoxicillin. E coli and Klebsiella maintained their known high production of ESBLs $^{31}$ with $24.69 \%$ and $30.77 \%$ respectively compared to the general $21.32 \%$.

This research showed from the analysis of the odds ratios of risks that poor sanitation at poultry site from environment to feeding predisposed chicken first to high bacterial carriage and secondly predisposed these 
bacteria to developing resistance, MDR and ESBLs. Though antibiotic use did not correlate as risk to these outcomes, it was because almost all poultries samples used antibiotics regularly making it a statistical constant. This is confirmed by Guetiya et al. $2016^{32}$. Correlation of these outcomes with "old age" of the chicken could be explained by the long duration of exposure to the risks ${ }^{33}$, the time to get infected or for coinfection to allow horizontal gene transfers.

This researched also showed that ESBL producing isolates that were quinolone resistant were significantly lower than those that were not quinolone resistant (32/84 against 52/84 respectively) while aminoglycoside isolates that were resistant to quinolones were significantly higher than those that were not quinolone resistant (43/66 against 23/66). This suggests that quinolone resistance could not be largely plasmid mediated because plasmid-carried quinolone resistance genes tend to occur with ESBL producing genes creating the opposite scenario ${ }^{29}$. This observation thus suggests a chromosomal DNA based quinolone resistance developed due to antibiotic misuse as noted in this study. Elena López et al. showed that ciprofloxacin induced chromosomal recombinations in $E$ coli enabled the bacterium to resist the drug ${ }^{10}$. However given the high association of aminoglycoside resistance to quinolone resistance, it suggests a shared rather than intrinsic mechanism such as plasmid mediated resistance but the lower overall prevalence of resistance to aminoglycosides shows a smaller contribution of this mechanism in the resistance observed $^{34,35}$.

\section{Conclusion}

This research showed that sub-standard hygienic conditions at poultries caused heavy Enterobacteriaceae carriage in chicken in the West Region of Cameroon with a fairly uniform distribution of organisms across the area of study. Enterobacteriaceae in this Region show high resistance to Penicillins and Tetracyclines. $3^{\text {rd }}$ generation Cephalosporins and Aminoglycosides proved to be drug classes of choice against Enterobacteriaceae with low resistance rates. The high resistance observed against quinolones calls for close monitoring of the use of these antibiotics in the community. The high prevalence of MDR and ESBL production especially in clinically important genera like Salmonella, Escherichia and Klebsiella indicate the necessity for stakeholders to put efforts and resources to combat misuse of antibiotics especially in animal farms. Further studies need to be conducted in this area on human subjects to evaluate same risk factors and consequences on the prevalence of resistance, MDR and ESBL production so as to do comparative studies and make more implication of this study on human populations.

\section{Methods}

\section{Aim}

The aim of this study was to contribute towards ameliorating the management and treatment of diseases linked to Enterobacteriaceae in Cameroon; providing epidemiological data on prevailing Enterobacteriaceae and their resistance patterns and risk factors. 


\section{Design}

The design used was a cross-section design.

\section{Study site}

The West Region with an area of $13,892 \mathrm{~km}^{2}$ is a territory located in the central-western portion of the Republic of Cameroon located at $5^{\circ} 30^{\prime} \mathrm{N} 10^{\circ} 30^{\prime} \mathrm{E}$. It borders the North West Region to the northwest, the Adamawa Region to the northeast, the Centre Region to the southeast, the Littoral Region to the southwest, and the Southwest Region to the west. The West Region is the smallest of Cameroon's ten regions in area, yet it has the highest population density; a population of $1,865,394$ (2013) with density of $134 / \mathrm{km}^{2}$. Its Capital is Bafoussam in the Mifi Division. It has 8 Divisions: Bamboutos, Upper-Nkam, Upper-Plateau, Koung-Khi, Ménoua, Mifi, Ndé and Noun ${ }^{36}$. The Region is found in the Grass field plateaus of the Western highlands with a cold climate and the main ethnic groups are the Bameliké and Bamoum ${ }^{22}$.

Laboratory work was carried out in the Research Unit of Microbiology and Antimicrobial Substances (RUMAS) in the University of Dschang.

\section{Sample collection}

In Cameroon, research on livestock is under the supervision of the Ministry of Livestock, Fisheries and Animal Industries (MINEPIA). Poultry and other livestock farms are registered under this Ministry which follows the health of the animals while still in the farm and before sales. A research authorisation (reference number 68/18/L/DREPIA-O/SRAG of 04/06/2018) addressed to the Divisional Delegates was obtained from the Regional Delegation of this Ministry. With the authorisation, the Divisional Delegates connected us to registered farms in the various Divisions. Consent from the farmers was verbal upon presentation of research authorisation and researchers' credentials and affiliations. The study was performed on cloacal swabs from healthy broiler chicken of any age from 28 farms in 11 locations in 5 out of the 8 Divisions of the West Region of Cameroon. We used stratified sampling with Divisions as the strata.

Cloacal swabs were collected by rubbing a $50 \mathrm{~cm}^{2}$ area of the cloaca with a sterile swab pre-wetted with physiological water. Each swab was immersed in $5 \mathrm{ml}$ of a sterile physiological solution in swab sampling tubes. The samples were transported in cool thermos flasks to the laboratory for analysis ${ }^{37}$.

\section{Sample enrichment and culture}

The swabs were dissolved in buffered peptone water and incubated for $24 \mathrm{hrs}$ at $38^{\circ} \mathrm{C}^{38}$. The enriched samples were cultured on EMB agar by plate streaking ${ }^{1}$ and incubated for 48 hours.

\section{Isolation of isolates and preservation}


Isolated colonies on the EMB agar were identified based on colony characteristics, picked and conserved in a conservation medium; a mixture of glycerol and Muller Hilton broth at 1 part : 3 parts and stored in a refrigerator ${ }^{39,40}$.

\section{Phenotypic characterisation of isolates}

A total of nine (9) rapid screening biochemical tests ${ }^{1,18}$ were performed on the isolates including: glucose and lactose fermentation, and hydrogen sulphide $\left(\mathrm{H}_{2} \mathrm{~S}\right)$ and gas production using Kligler Iron Agar ( $\left.\mathrm{KIA}\right)$, urease activity and indole production using urea broth and Kovacs' reagent, mannitol fermentation and motility using mannitol agar, and citrate fermentation using citrate agar.

\section{Antibiotic susceptibility testing}

Fresh colonies were used to prepare $0.5 \mathrm{McF}$ arland solution inoculums using sterile physiological water. Antibiotic susceptibility testing was carried out on Mueller Hilton Agar by the Kirby-Bauer disc diffusion method ${ }^{2,18}$. Screening for antibiotic resistance in the isolates was done using following antibiotics ${ }^{41}$ :

\begin{tabular}{|ll|}
\hline Class & Antibiotics \\
\hline Beta lactamins & Amoxicillin, amoxicillin/clavulanic acid, ceftriaxone, cefotaxime and imipenem \\
\hline Aminoglycosides & Gentamicin and amikacin \\
\hline Quinolones & Ciprofloxacin and levofloxacin \\
\hline Tetracycline & Doxycycline \\
\hline
\end{tabular}

Phenotypic determination of resistance by penicillinase production was tested by combination disc test with amoxicillin/clavulanic acid with comparison to amoxicillin. Extended spectrum beta-lactamase production was tested by observing resistance to amoxicillin followed by resistance to ceftriaxone or cefotaxime ${ }^{42}$, and then the double disc synergy test was conducted by placing the ceftriaxone or cefotaxime $3 \mathrm{~cm}$ from amoxicillin/clavulanic acid giving a clear zone of intersection between the two discs ${ }^{43}$.

\section{DATA ANALYSIS}

\section{Interpretation of phenotypic reactions}

This research work generated information on Enterobacteriaceae carriage in broilers, identity of Enterobacteriaceae organisms, their prevalence, their antibiotic susceptibility profiles (susceptible, resistant, multidrug resistant and ESBL producing) and, odds ratios and correlations between outcomes (Enterobacteriaceae carriage, prevalence, resistance, MDR and ESBL production) and risks. 
Enterobacteriaceae carriage was determined by the count of the different colonies on the Enterobacteriaceae specific growth medium (EMB agar) based on colony aspect and morphology. The identity of the organism was gotten by interpreting the colony aspect and the results of the phenotypic reactions using a KIA user guide alongside the identification software: Feuille de calcule pour l'identification microbienne developed by J-Noël JOFFIN (8 Dec 2007 version). Susceptibility to antibiotics was evaluated using standard values as given by Sigma Aldrich ${ }^{\circledR 4}$. MDR was assessed as resistance of an isolate to two or more antibiotics belonging antibiotic classes of choice used against Enterobacteriaceae (cephalosporins, carbapenems, quinolones or aminoglycosides). ESBL production was interpreted from double disc synergy test between amoxicillin/clavulanic acid disc and ceftriaxone or cefotaxime disc.

Simple arithmetic operations and conversions were done using Microsoft Excel sheets while frequencies, prevalence, odds ratios, correlations and diagrams were done using IBM SPSS Statistics 20.

\section{Abbreviations}

Cl: confidence interval

EMB: eosin methylene blue

ESBL: extended spectrum beta lactamase

KIA: Kligler Iron Agar

MDR: multidrug resistance

MINEPIA: French acronym for Ministry of Livestock, Fisheries and Animal Industries

RUMAS: Research Unit of Microbiology and Antimicrobial Substances

\section{Declarations}

\section{Ethical consideration}

This study did not involve active participation of the fowls and sampling by cloacal swabs was a non-invasive procedure.

Working with poultry farms falls under the authorities of the Ministry of Livestock, Fisheries and Animal Industries (MINEPIA), thus an authorisation (authorisation reference number 68/18/L/DREPIA-O/SRAG of 04/06/2018) to sample chicken within the West Region was obtained from the Regional Delegation of MINEPIA which also helped to enable collaboration with its Divisional Delegates and farmers.

\section{Consent for publication}

Not applicable 


\section{Availability of data}

The datasets generated during the present study are presented in this manuscript. Any other raw data are available from the corresponding author upon a reasonable request.

\section{Conflicting interest}

The authors declare that they have no conflicting interests.

\section{Funding}

The authors of the study funded field work and sample collection, purchase of part of reagents and materials used. The Department of Biochemistry, University of Dschang funded costs of laboratory equipment and reagents and laboratory running costs. Some funds available for the research came from the yearly grants to research students by the government of Cameroon.

\section{Authors' contribution}

Leinyuy Jude Fonbah: Field work and laboratory analysis, data analysis and writing of the article.

Innocent Mbulli Ali: Study conception, designed protocols for laboratory analysis, supervised field and laboratory analysis, interpreted data and reviewed the manuscript.

Ousenu Karimo: Performed laboratory analysis, data analysis interpretation and drafting section of the manuscript.

Christopher B. Tume: Study conception, supervision and manuscript review.

\section{ACKNOWLEDGEMENT}

Our gratitude goes to:

- The University of Dschang, the Faculty of Science and particularly the Department of Biochemistry with its staff, whose guidance and collaboration were indispensable to the success of this project,

- The University run Research Unit of Microbiology and Antimicrobial Substances (RUMAS) that provided the work space, and

- Field agents and farmers for their collaboration.

\section{References}

1. Kathleen Park Talaro and Barry Chess. Foundations in Microbiology. $4^{\text {th }}$ Edition. McGraw-Hill. 2002. ISBN-13: 978-0072320428. 
2. Subhash Chandra Parija. Textbook of Microbiology and Immunology. $2^{\text {nd }}$ Edition, Manesar. ELSEVIER. 2012. ISBN: 978-81-312-2810-4.

3. Garza-Gonza'lez E, Mendoza Ibarra SI, Llaca-Dı'az JM and Gonzalez G M. Molecular characterization and antimicrobial susceptibility of extended-spectrum $\beta$ - lactamase producing Enterobacteriaceae isolates at a tertiary care centre in Monterrey, Mexico. Journal of Medical Microbiology. 2011; 60, 84-90 DOI 10.1099/jmm.0.022970-0.

4. Aav.org. Zoonotic Diseases in Backyard Poultry. Association of avian veterinarians. Available from https://www.aav.org/page/poultryzoonotic. Accessed on 15/10/2020.

5. Engidaw Abebe, Getachew Gugsa, Meselu Ahmed. Review on Major Food-Borne Zoonotic Bacterial Pathogens. Journal of Tropical Medicine, vol. 2020, Article ID 4674235, 19 pages, 2020. https://doi.org/10.1155/2020/4674235.

6. Biggs PM. The world of poultry disease. Avian Pathology, 1982; 11:2, 281-300. DOI: 10.1080/03079458208436101.

7. Nhung NT, Chansiripornchai N and Carrique-Mas JJ. Antimicrobial Resistance in Bacterial Poultry Pathogens: A Review. Front. Vet. Sci. 2017;4:126. doi: 10.3389/fvets.2017.00126.

8. Elong Ekambi, Grace-Ange et al. "Knowledge, practices and attitudes on antibiotics use in Cameroon: Selfmedication and prescription survey among children, adolescents and adults in private pharmacies." PloS one vol. 14,2 e0212875. 28 Feb. 2019, doi:10.1371/journal.pone.0212875.

9. Carlet J. The gut is the epicentre of antibiotic resistance. Antimicrob Resist Infect Control. 2012 Nov 27;1(1):39. doi: 10.1186/2047-2994-1-39. PMID: 23181506; PMCID: PMC3554492.

10. López E, Elez M, Matic I, Blázquez J. Antibiotic-mediated recombination: ciprofloxacin stimulates SOSindependent recombination of divergent sequences in Escherichia coli. Mol Microbiol. 2007; 64(1):83-93. doi:10.1111/j.1365-2958.2007.05642.x.

11. Goodyear KL. Antimicrobial Resistance Coordination Group. Veterinary surveillance for antimicrobial resistance. J Antimicrob Chemother. 2002 Oct;50(4):612-4. doi: 10.1093/jac/dkf154. PMID: 12356812.

12. Khan PV, Lontuo FR, Ngangnang GR, Megwi L. Prevalence and Intensity of Infection of Gastro-Intestinal Parasites in Babadjou, West Region of Cameroon. International Journal of Clinical and Experimental Medical Sciences. 2017. 3(2):14. January 2017. DOI: 10.11648/j.ijcems.20170302.11.

13. Enow Orock G, Enow Orock A, Ngounou E, Konang N J, Noubom M, Nzeukou E, Tabeu Nm and Luma H. Gastrointestinal Pathologies in a Center with Limited Resources: Pilot Study at Bafoussam Regional Hospital, Cameroon. J Surg Insights. 2020. JSI-100022. 03 August, 2020. ISSN 2652-4643.

14. Mouiche MMM, Moffo F, Akoachere JTK, Okah-Nnane NH, Mapiefou NP, Ndze VN, et al. J. Antimicrobial resistance from a one health perspective in Cameroon: a systematic review and meta-analysis. BMC Public Health. 2019 Aug 19;19(1):1135. doi: 10.1186/s12889-019-7450-5. PMID: 31426792; PMCID: PMC6700798.

15. Awono Cyprien, Laroche DC, Havard M \& Vermersch D. Marché du poulet au Cameroun : Analyse en équilibre partiel des effets de l'ouverture aux importations. Revue scientifique 2007 de l'Institut de Recherche Agricole pour le Développement « La recherche agricole dans le processus d'intégration régionale d’Afrique Centrale » Palais des Congrès, 2 au 4 juillet 2007, Yaoundé, Cameroun. 
16. AMARAL, LA do. Drinking water as a risk factor to poultry health. Rev. Bras. Cienc. Avic., Campinas. 2004, v. 6, n. 4, p. 191-199, Dec. 2004. Available from <http://www.scielo.br/scielo.php? script=sci_arttext\&pid=S1516-635X2004000400001\&lng=en\&nrm=iso>. Accessed on 22 Oct. 2020. https://doi.org/10.1590/S1516-635X2004000400001.

17. Yoni Segal. Prevention and Control of poultry diseases For better farm profitability. FAO Consultant yoni.segal@fao.org. Available at http://www.fao.org/3/al875e/al875e00.pdf. Visited on the 19/10/2020 at $17: 14$.

18. Champoux JJ, Drew LW, Neidhardt CF \& Plorde JJ. Sherris Medical Microbiology: An Introduction to Infectious Diseases 4th Edition. New York. McGraw-Hill Medical Publishing. 2004.

19. Guentzel MN. Escherichia, Klebsiella, Enterobacter, Serratia, Citrobacter, and Proteus. In: Baron S, editor. Medical Microbiology. 4th edition. Galveston (TX): University of Texas Medical Branch at Galveston; 1996. Chapter 26. Available from: https://www.ncbi.nlm.nih.gov/books/NBK8035/.

20. Ahmed AO, Raji MA, Mamman PH, Kwanashie CN, Raufu IA, Aremu A, Akorede GJ. Salmonellosis: Serotypes, prevalence and multi-drug resistant profiles of Salmonella enterica in selected poultry farms, Kwara State, North Central Nigeria. Onderstepoort J Vet Res. 2019 May 30;86(1):e1-e8. doi: 10.4102/ojvr.v86i1.1667. PMID: 31170784; PMCID: PMC6556926.

21. Robert J, Cambau E, Grenet K, Péan Y, Fiévet MH, Jarlier V. Trends in quinolone susceptibility of Enterobacteriaceae among inpatients of a large university hospital: 1992-98. Clinical Microbiology and Infection. 2001. Volume 7, Issue 10, P553-561, October 01, 2001. DOI: https://doi.org/10.1046/j.1198743x.2001.00322.x.

22. Jacques CHAMPAUD. Villes et campagnes du Cameroun de l'Ouest. Université de Bordeaux III Institut de Géographe et d'Etudes Régionales. Thèse de Doctorat d'Etat. https://core.ac.uk/download/pdf/39877633.pdf.

23. Tago KG, Ouattara H, Bakayoko S. Prevalence of Salmonella and distribution of Serovars Isolated from Retail Raw Chicken Gizzards in Abidjan, Côte D’ivoire. Octa. J. Biosci. 2013. Vol. 1(2): 115-121. ISSN 2321 $-3663$.

24. Gad GF, Mohamed HA, Ashour HM. Aminoglycoside resistance rates, phenotypes, and mechanisms of Gram-negative bacteria from infected patients in upper Egypt. PLoS One. 2011 Feb 17;6(2):e17224. doi: 10.1371/journal.pone.0017224. PMID: 21359143; PMCID: PMC3040769.

25. Sebastien Breurec, Coralie Bouchiat, Jean-Marie Sire, Olivier Moquet, Raymond Bercion. High thirdgeneration cephalosporin resistant Enterobacteriaceae prevalence rate among neonatal infections in Dakar, Senegal. BMC Infectious Diseases, BioMed Central, 2016, 36, pp.408 - 408. ff10.1186/s12879- 0161935-yff. ffhal-01473613f.

26. Leski TA, Taitt CR, Bangura U, Stockelman MG, Ansumana R, Cooper WH, Stenger DA, Vora GJ. High prevalence of multidrug resistant Enterobacteriaceae isolated from outpatient urine samples but not the hospital environment in Bo, Sierra Leone. BMC Infect Dis. 2016 Apr 18;16:167. doi: 10.1186/s12879-0161495-1. PMID: 27090787; PMCID: PMC4836052.

27. Chopra I, Roberts M. Tetracycline antibiotics: mode of action, applications, molecular biology, and epidemiology of bacterial resistance. Microbiol Mol Biol Rev. 2001 Jun;65(2):232-60 ; second page, table of contents. doi: 10.1128/MMBR.65.2.232-260.2001. PMID: 11381101; PMCID: PMC99026. 
28. Girlich D, Bonnin RA, Dortet L, Naas T. Genetics of Acquired Antibiotic Resistance Genes in Proteus spp. Front Microbiol. 2020 Feb 21; 11:256. doi: 10.3389/fmicb.2020.00256. PMID: 32153540; PMCID: PMC7046756.

29. Azargun R, Sadeghi MR, Soroush Barhaghi MH, et al. The prevalence of plasmid-mediated quinolone resistance and ESBL-production in Enterobacteriaceae isolated from urinary tract infections. Infect Drug Resist. 2018;11:1007-1014. Published 2018 Jul 23. doi:10.2147/IDR.S160720.

30. Kate Gould, Antibiotics: from prehistory to the present day. Journal of Antimicrobial Chemotherapy. 2016; Volume 71, Issue 3, March 2016, Pages 572-575, https://doi.org/10.1093/jac/dkv484.

31. Tim Jewell, Alana Biggers. ESBL (extended spectrum beta-lactamases). Healthline https://www.healthline.com/health/esbl.Updated on April 14, 2017.

32. Guetiya Wadoum RE, Zambou NF, Anyangwe FF, Njimou JR, Coman MM, Verdenelli MC, Cecchini C, Silvi S, Orpianesi C, Cresci A, Colizzi V. Abusive use of antibiotics in poultry farming in Cameroon and the public health implications. Br Poult Sci. 2016 Aug;57(4):483-93. doi: 10.1080/00071668.2016.1180668. Epub 2016 Jun 29. PMID: 27113432.

33. Ursula J. Blumenthal, Jay M. Fleisher, Steve A. Esrey and Anne Peasey. Water Quality: Guidelines, Standards and Health. Chapter 7 Epidemiology: a tool for the assessment of risk. ( 2001 World Health Organization (WHO). Edited by Lorna Fewtrell and Jamie Bartram. Published by IWA Publishing, London, UK. ISBN: 190022228 0. https://www.who.int/water_sanitation_health/dwq/iwachap7.pdf.

34. Shaw KJ, Rather PN, Hare RS, Miller GH. Molecular genetics of aminoglycoside resistance genes and familial relationships of the aminoglycoside-modifying enzymes. Microbiol Rev. 1993;57(1):138-163. doi:10.1128/mr.57.1.138-163.1993.

35. Huang S, Dai W, Sun S, Zhang X, Zhang L. Prevalence of Plasmid-Mediated Quinolone Resistance and Aminoglycoside Resistance Determinants among Carbapeneme Non-Susceptible Enterobacter cloacae. PLOS ONE. 2012; 7(10): e47636. https://doi.org/10.1371/journal.pone.0047636.

36. West Region of Cameroon. Available from en.m.wikipedia.org/wiki/West_Region_Cameroon. Accessed on $17 / 10 / 2020$.

37. FAO. Disease sampling procedures' in WILD BIRDS AND AVIAN INFLUENZA; An introduction to applied field research and disease sampling techniques. FAO Animal Production and Health Manual (C) FAO 2007 Pp 73 - 85. Available from http://www.fao.org/3/a1521e/a1521e00.htm. Accessed on 12/03/2019 at $14: 38$.

38. Hoorfar J, Baggesen DL. Importance of pre-enrichment media for isolation of Salmonella spp. from swine and poultry. FEMS Microbiology Letters. 1998. Volume 169, Issue 1, December 1998, Pages 125-130, https://doi.org/10.1111/j.1574-6968.1998.tb13308.x.

39. Dagny J L, Jerry RR, Elvinger F. Use of eosin methylene blue agar to differentiate Escherichia coli from other gram-negative mastitis pathogens. J Vet Diagn Invest. 2001. 13: 273-275.

https://journals.sagepub.com/doi/pdf/10.1177/104063870101300319.

40. Scientific protocols. Long Term Storage of Bacterial Strains. https://protocols.scienceexchange.com/users/scientificprotocols: DOI: 10.5281/zenodo.13545. Updated 2014-08-18. Accessed on the 18/04/2019. 
41. Mahaluca FA, Essack S, Zimba T, Sacarlal J. Profile of Antibacterial Resistance of the Enterobacteriaceae Family in Pediatric and Adult Patients. Ann Clin Immunol Microbiol. 2019; 1(2): 1007.

42. Iqbal Rashid, Nadeem I, Muhammad S, Muhammad JA, Raja TM, Abida N, et al. Phenotypic confirmatory disc diffusion test (PCDDT), double disc synergy test (DDST), E-test OS diagnostic tool for detection of extended spectrum beta lactamase (ESBL) producing Uropathogens. J Appl Biotechnol Bioeng. 2017; 3(3):344-349. DOI: 10.15406/jabb.2017.03.00068.

43. Legrand, P., Fournier, G., Buré, A. et al. Detection of extended broad-spectrum beta-lactamases in Enterobacteriaceae in four French hospitals. Eur. J. Clin. Microbiol. Infect. Dis. 8, 527-529 (1989). https://doi.org/10.1007/BF01967473.

44. Sigma. Antimicrobial susceptibility discs leaflet. Available from https://www.sigmaaldrich.com/content/dam/sigma-Idrich/docs/Sigma/General_Information/ antimicrobial_suscept_discs_leaflet.pdf. Accessed on 05/10/2020.

\section{Tables}

Due to technical limitations, table 3 and table 4 are only available as a download in the Supplemental Files section.

\section{Figures}




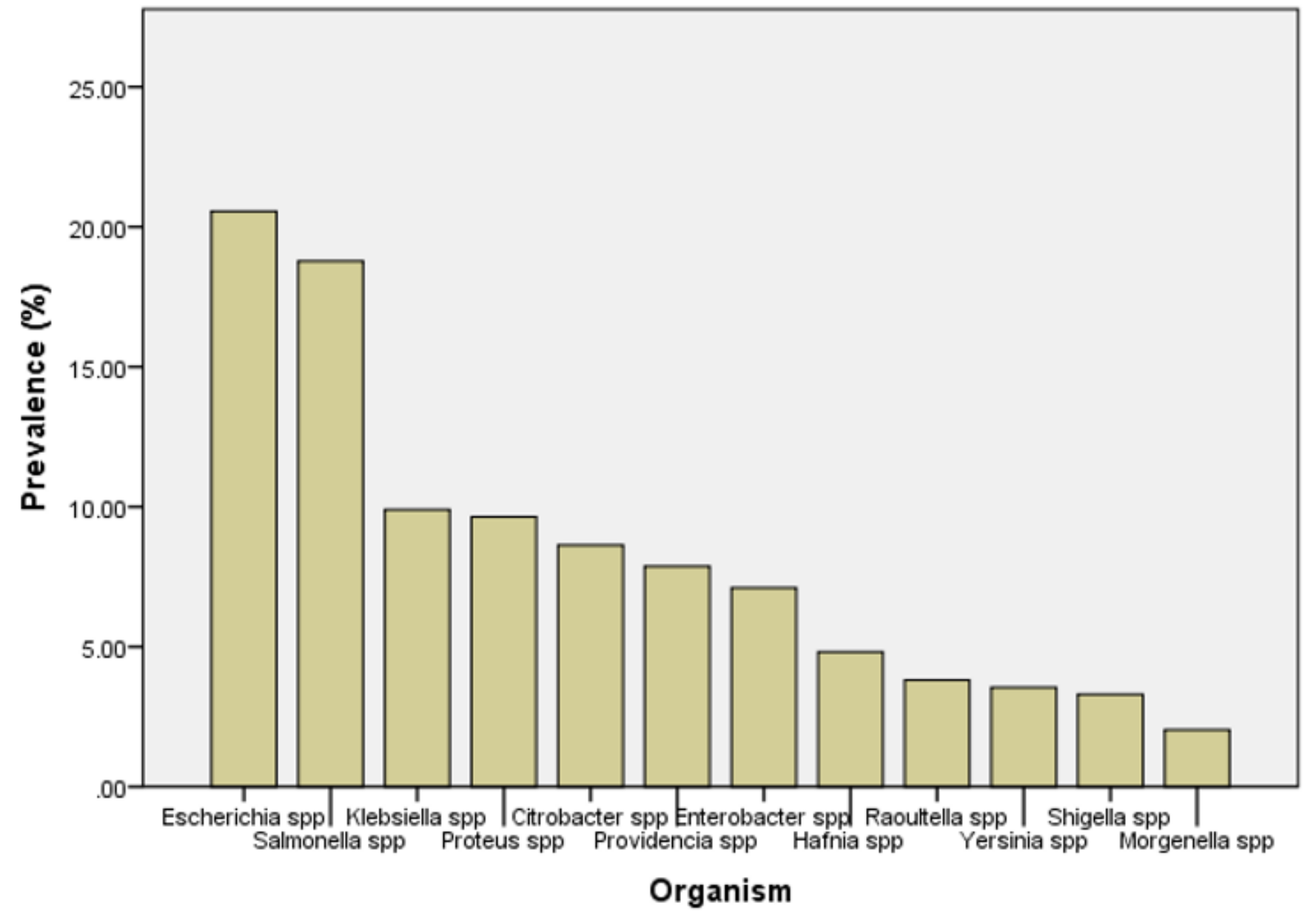

Figure 1

Prevalence of isolates of different Enterobacteriaceae species 


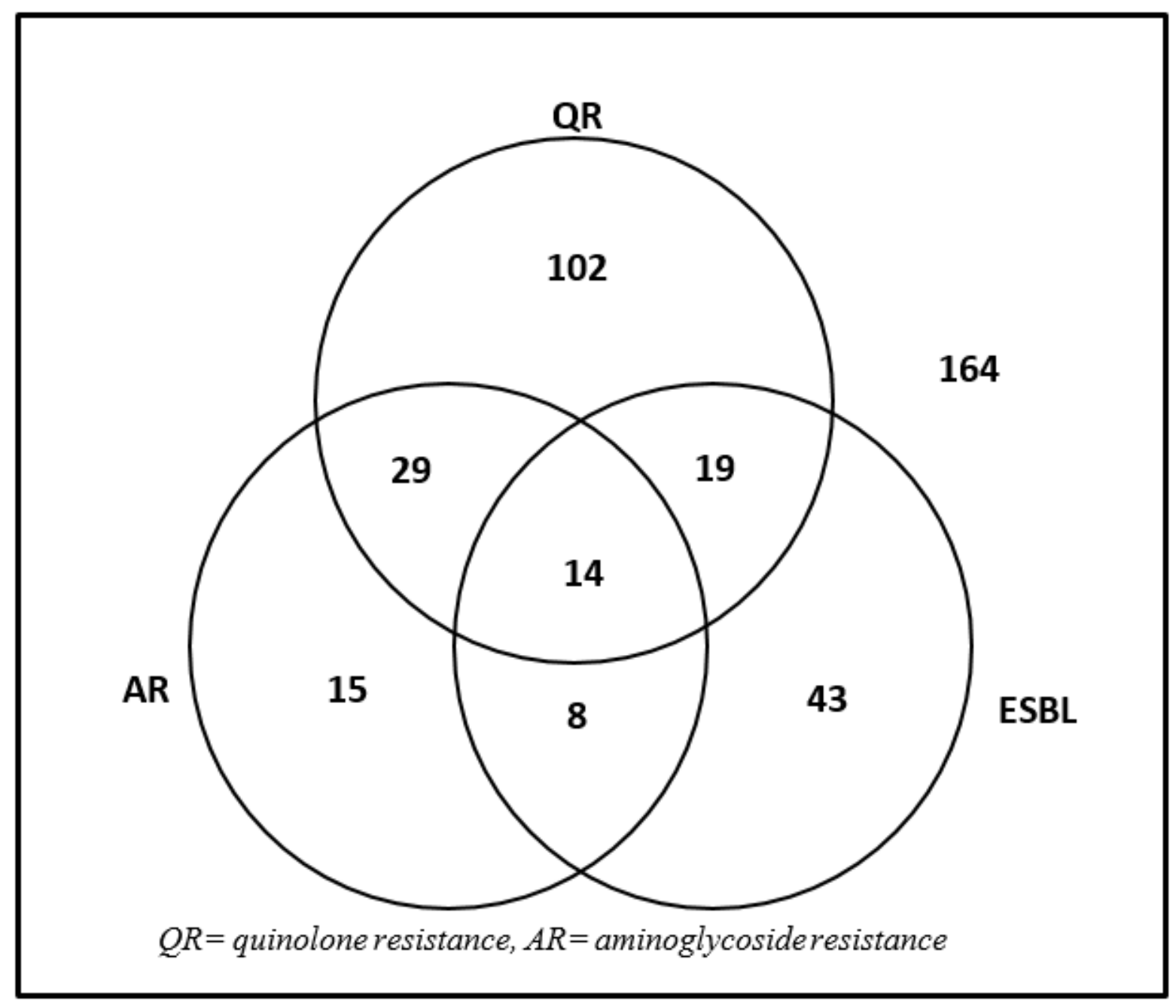

Figure 2

Association of various resistance phenotypes among isolates 


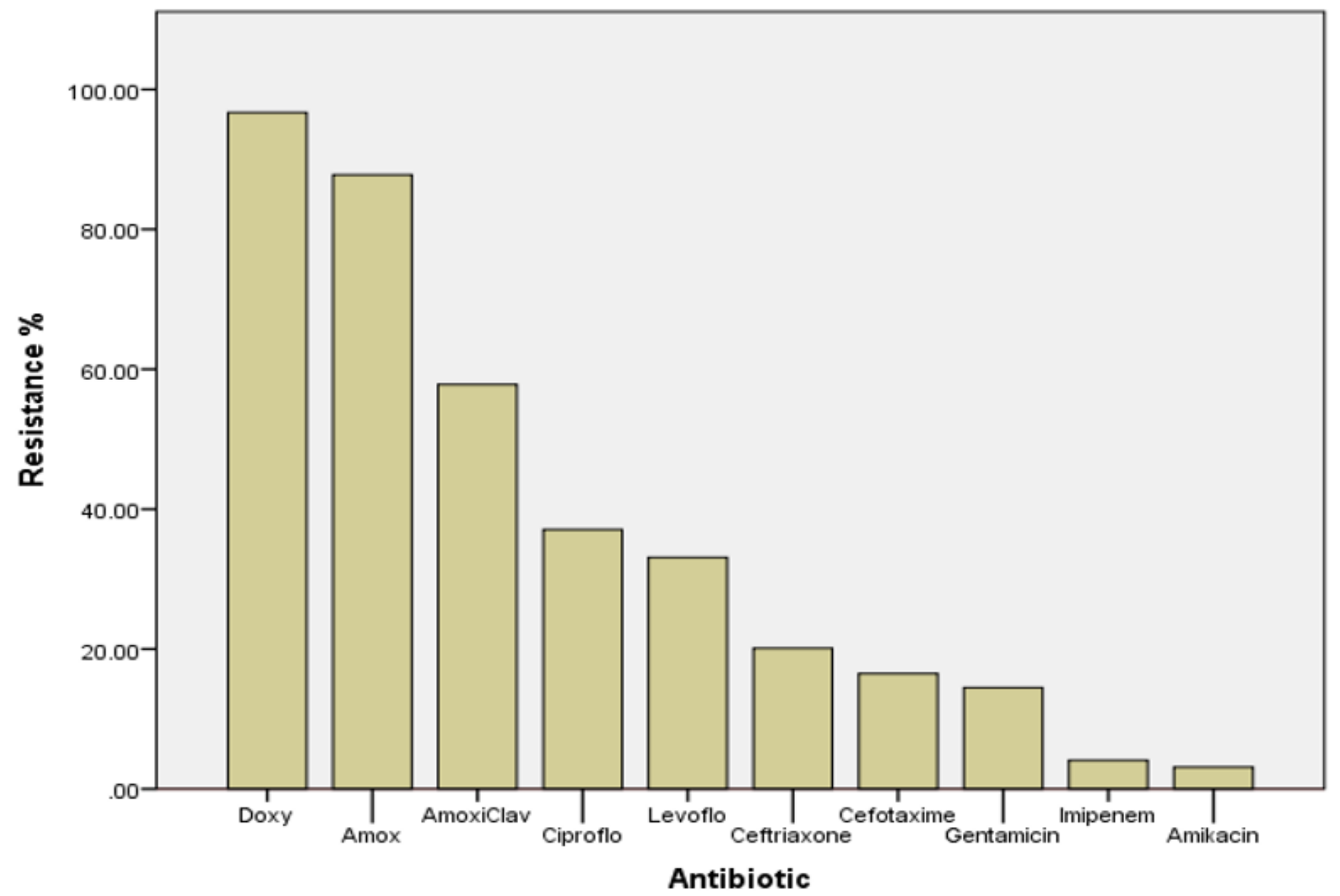

Figure 3

General prevalence of resistance of isolates to various antibiotics tested 


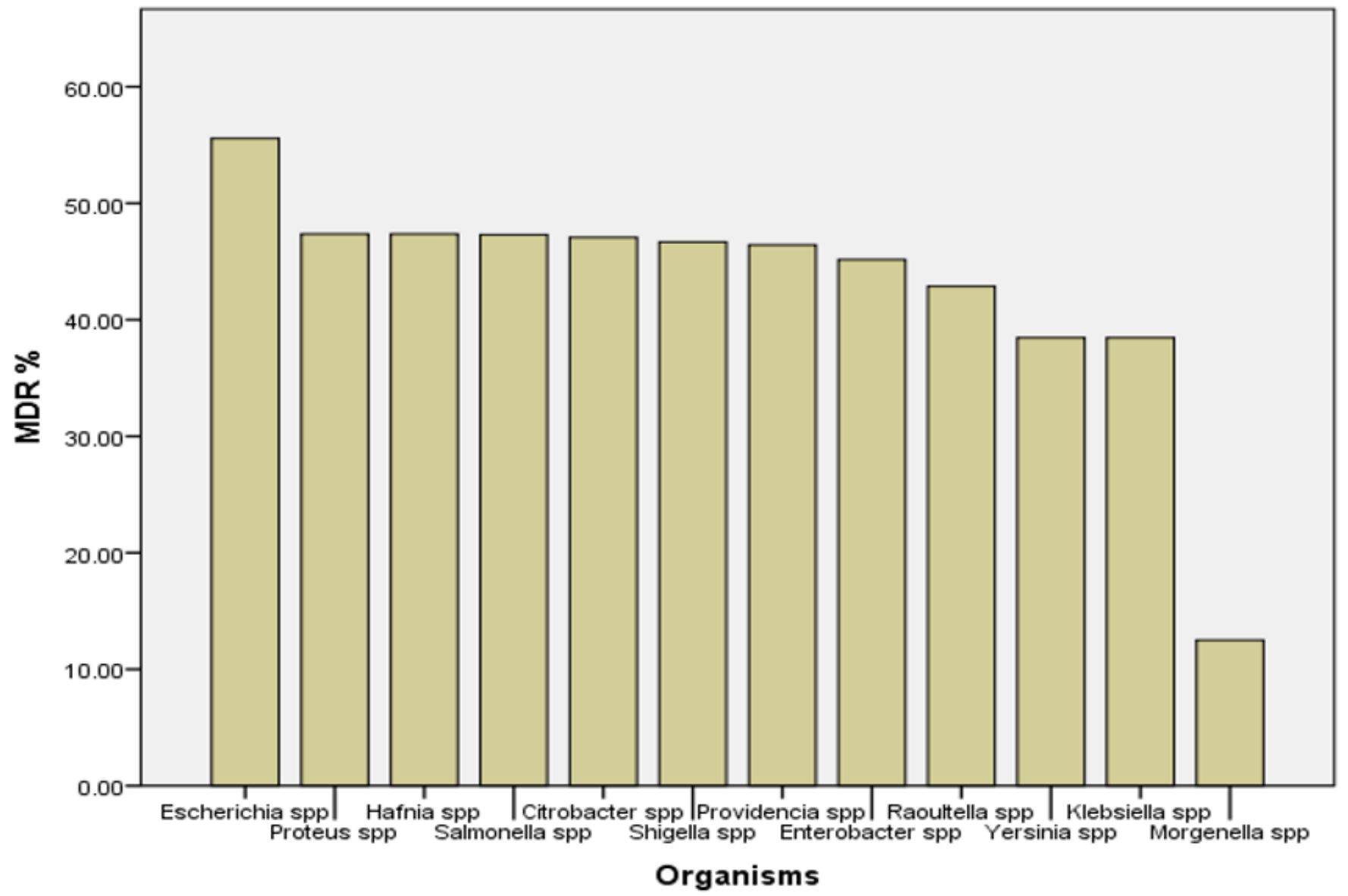

Figure 4

General prevalence of MDR amongst the isolates 


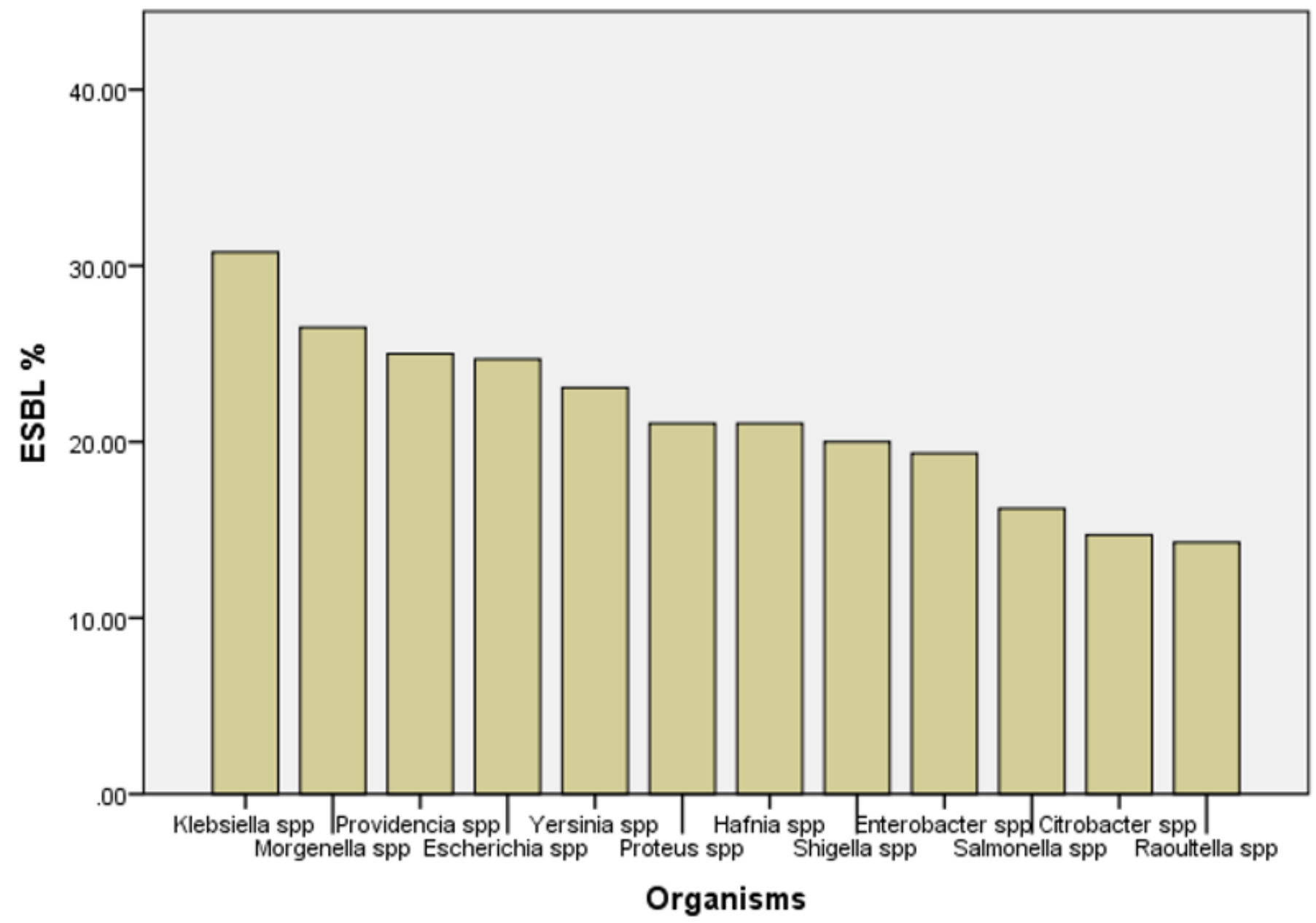

Figure 5

General prevalence of ESBL production among the isolates 


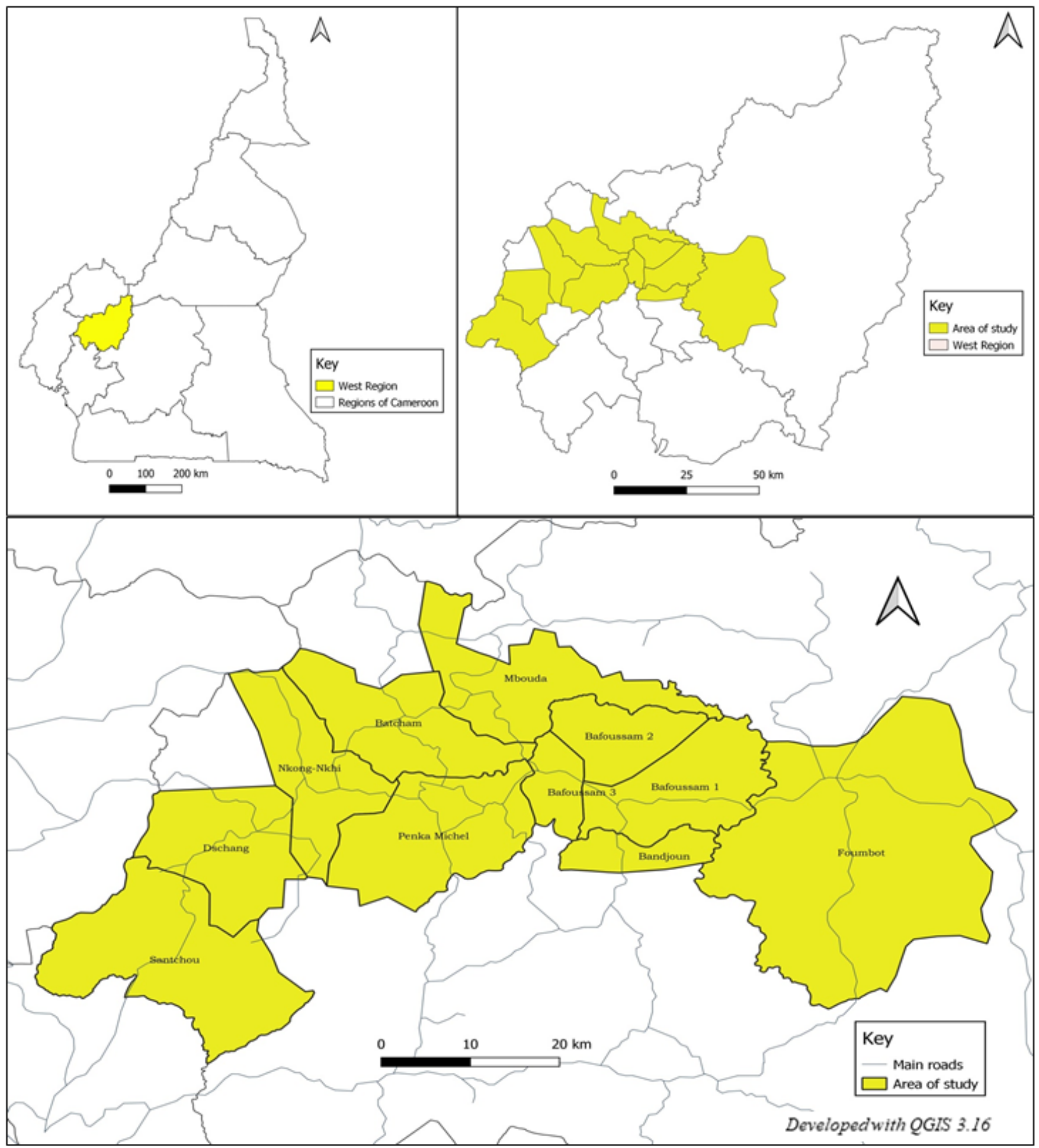

Figure 6

Localisation of the study area 


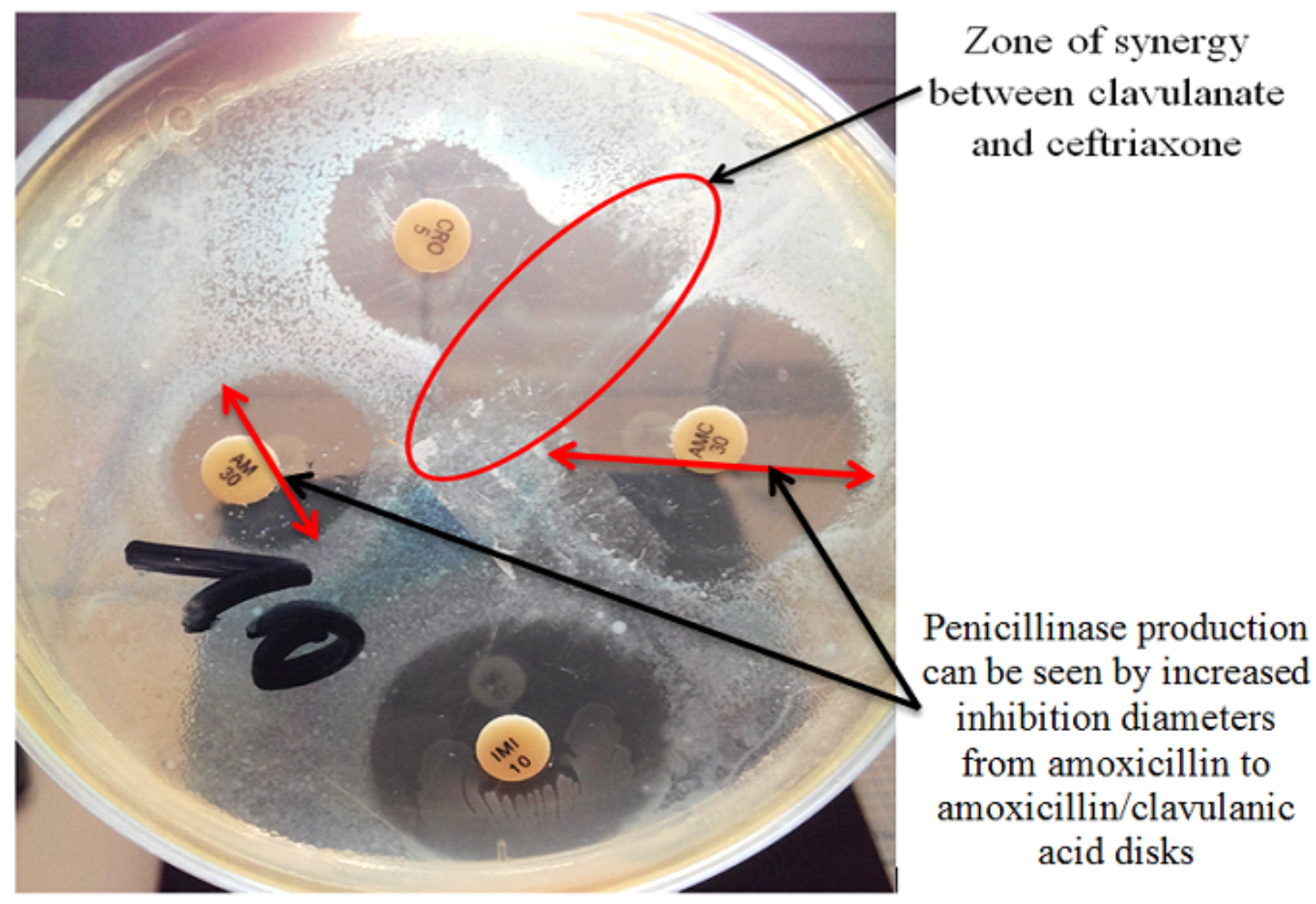

Figure 7

Antibiogram disc showing penicillinase and ESBL production

\section{Supplementary Files}

This is a list of supplementary files associated with this preprint. Click to download.

- Table3line111.docx

- Table4line128.docx 